\title{
Genetic diversity of gliadin alleles in bread wheat (Triticum aestivum L.) from Northern Kazakhstan
}

\author{
Maral Utebayev ${ }^{\text {Corresp., } 1,2}$, Svetlana Dashkevich ${ }^{1}$, Nina Bome $^{2}$, Kulpash Bulatova ${ }^{3}$, Yuri Shavrukov ${ }^{4}$ \\ 1 A.I.Baraev Research and Production Centre of Grain Farming, Shortandy, Kazakhstan \\ 2 Institute of Biology, University of Tyumen, Tyumen, Russia \\ 3 Kazakh Research Institute of Agriculture and Plant Growing, Almaty region, Kazakhstan \\ ${ }^{4}$ College of Science and Engineering, School of Biological Sciences, Flinders University, Bedford Park, SA, Australia \\ Corresponding Author: Maral Utebayev \\ Email address: phytochem@yandex.ru
}

Background: Spring bread wheat (Triticum aestivum L.) represents the main cereal crop in Northern Kazakhstan. The quality of wheat grain and flour strongly depends on the structure of gluten, comprised of gliadin and glutenin proteins. Electrophoresis spectra of gliadins are not altered by environmental conditions or plant growth, are easily reproducible and very useful for wheat germplasm identification in addition to DNA markers. Genetic polymorphism of two Gli loci encoding gliadins can be used for selection of preferable genotypes of wheat with high grain quality.

Methods: Polyacrylamide gel electrophoresis was used to analyse genetic diversity of gliadins in a germplasm collection of spring bread wheat from Northern Kazakhstan.

Results: The highest frequencies of gliadin alleles were found as follows, in Gli1: $-A 1 \boldsymbol{f}(39.3 \%),-B 1 \boldsymbol{e}$ (71.9\%), and - D 1 a (41.0\%); and in Gli-2: - $A 2$ q (17.8\%), - B 2 t (13.5\%), and - D 2 q (20.4\%). The combination of these alleles in a single genotype may be associated with higher quality of grain as well as better adaptation to the dry environment of Northern Kazakhstan; preferable for wheat breeding in locations with similar conditions. 


\section{Genetic diversity of gliadin alleles in bread wheat (Triticum aestivum L.) from}

\section{Northern Kazakhstan}

3

4 Maral Utebayev $^{1,2 *}$, Svetlana Dashkevich ${ }^{1}$, Nina Bome ${ }^{2}$, Kulpash Bulatova ${ }^{3}$, Yuri Shavrukov ${ }^{4}$ 5

$6{ }^{1}$ A.I. Barayev Research and Production Centre of Grain Farming, Shortandy, Kazakhstan;

$7{ }^{2}$ Institute of Biology, University of Tyumen, Tyumen, Russia;

$8{ }^{3}$ Kazakh Research Institute of Agriculture and Plant Growing, Almaty Region, Kazakhstan;

$9{ }^{4}$ College of Science and Engineering, School of Biological Sciences, Flinders University, SA, 10 Australia;

* Correspondence: Maral Utebayev. E-mail: phytochem@yandex.ru

\section{Abstract}

15 Spring bread wheat (Triticum aestivum L.) represents the main cereal crop in Northern

16 Kazakhstan. The quality of wheat grain and flour strongly depends on the structure of gluten, 17 comprised of gliadin and glutenin proteins. Electrophoresis spectra of gliadins are not altered by environmental conditions or plant growth, are easily reproducible and very useful for wheat germplasm identification in addition to DNA markers. Genetic polymorphism of two Gli loci encoding gliadins can be used for selection of preferable genotypes of wheat with high grain quality. Polyacrylamide gel electrophoresis was used to analyse genetic diversity of gliadins in a germplasm collection of spring bread wheat from Northern Kazakhstan. The highest frequencies of gliadin alleles were found as follows, in Gli1: $-A 1 f(39.3 \%),-B 1 \boldsymbol{e}(71.9 \%)$, and $-D 1 \boldsymbol{a}(41.0 \%)$; and in Gli-2: $-A 2 \boldsymbol{q}(17.8 \%),-B 2 \boldsymbol{t}(13.5 \%)$, and $-D 2 \boldsymbol{q}(20.4 \%)$. The combination of these alleles in a single genotype may be associated with higher quality of grain as well as better adaptation to the dry environment of Northern Kazakhstan; preferable for wheat breeding in locations with similar conditions. 


\section{Introduction}

Wheat flour remains one of main ingredients in quite a diverse range of foods for human consumption and provides the major proteins gliadins and glutenins. In particular, glutenin can make up at least $40 \%$ of the total protein in grain and flour (Qi et al., 2006; Metakovsky et al., 2018). The genetic control of gliadin includes two major genes, Gli-1 and Gli-2, mapped to the short arms of chromosome groups 1 and 6 , respectively, with corresponding homeologous genes, Gli-A1, -B1, -D1 and Gli-A2,-B2,-D2 (Metakovsky, Branlard \& Graybosch, 2006; Metakovsky et al., 2018). Multiple alleles are typically found for both Gli loci. Each Gli allele encodes the transcription of clusters of subunits, with several components of gliadin proteins showing linked inheritance. Gliadin groups can differ in the number of components, their electrophoretic mobility and molecular weight, and levels of expression (Sozinov \& Poperelya, 1980; Obukhova \& Shumny, 2016). By its nature, gliadin is a complex protein with several components that can be separated using polyacrylamide gel electrophoresis in aluminium-lactate buffer $(\mathrm{pH}=3.1)$ (Bushuk \& Zillman, 1978). The original protocol of gliadin electrophoresis has been since modified (Tkachuk \& Metlish, 1980; Khan, Hamada \& Patek, 1985; Metakovsky \& Novoselskaya, 1991), and was used as the basis for the International standard procedure ISO (ISO 1993). Gli alleles and their components have been widely studied and identified in International wheat germplasm collections, resulting in published Catalogues. The genetic polymorphism in the composition of Gli alleles in a given genotype was summarised as the 'Gliadin genetic formula' (GGF) in the Catalogues for bread wheat (Metakovsky, 1991; Metakovsky et al., 2018) and for durum wheat (Melnikova, Kudryavtseva \& Kudryavtsev, 2012).

As reported in many publications, wheat cultivars produced in each separate country often have similar GGF despite the absence of any selection pressure based on gliadins (Xynias, Kozub \& Sozinov, 2006; Aguiriano et al., 2008; Salavati et al., 2008; Melnikova et al., 2010; Novoselskaya-Dragovich et al., 2011; Hailegiorgis et al., 2017). A linkage between Gli alleles and other genes or a group of genes encoding favourable traits can be preferable and beneficial for wheat breeding (Chebotar et al., 2012). Therefore, a high frequency of Gli alleles can be used as simple and convenient method based on protein marker analysis for wheat germplasm identification and application in further breeding programs in the same environment. 
60 Currently, molecular markers based on DNA analysis are widely used for genotyping and genetic identification in various crops (Shavrukov, 2016; Jatayev et al., 2017; Scheben, Batley \& Edwards, 2017; Burridge et al., 2018). The application of molecular markers was successful in

63

64 65 the study of wheat genes controlling such traits as 1000-grain weight, protein and gluten content (Zhang et al., 2018), grain hardness (Nirmal et al., 2016), flour production from grain milling (Nirmal et al., 2017), and bread quality (Henry, Furtado \& Rangan, 2018). Genome editing using CRISPR/Cas9 technology represents a novel method in plants (Khlestkina \& Shumny, 2016; Liang et al., 2018; Borisjuk et al., 2019), for production of wheat with low gluten content (Sánchez-León et al. 2018), as required by people allergic to some components of gliadin in traditional wheat cultivars (Palosuo et al., 2001; Pastorello et al., 2007).

Nevertheless, molecular markers are relatively expensive in the equipment and reagents required, in typically well-established molecular laboratories. In contrast, biochemical markers based on proteins such as enzymes and storage proteins offer an alternative method involving cheaper and simpler protocols for crop breeding including wheat (Shewry \& Halford, 2001; Ghanti et al., 2009; Al-Doss et al., 2010; Netsvetaev, Akinshina \& Bondarenko, 2010; Hailegiorgis, Lee \& Yun, 2017). Additionally, protein synthesis is encoded by genes, and modulation of gene expression in response to changes in the environment directly results in different levels of the corresponding proteins.

The aim of this study was to identify and analyse the genetic diversity of the Gli alleles in spring bread wheat (Triticum aestivum L.) collection from Northern Kazakhstan, and to address the question of which alleles of gliadins with highest frequencies are typical for modern wheat produced and cultivated in the dry environment of this region.

\section{Materials and Methods}

\section{Wheat germplasm and geographic locations}

87 A seed collection of 70 bread wheat cultivars was provided by the A.I. Barayev Research and

8 Production Centre of Grain Farming, Shortandy, Kazakhstan. The studied wheat accessions were

89 bred and produced at different times by Breeding Institutions (Karabalyk Agricultural Breeding 
90 Station and Pavlodar Research Institute of Agriculture) in Northern Kazakhstan, as listed in

91 Supplementary material 1. Additional data for various wheat germplasms from Kazakhstan and 92 neighbouring regions, used for comparison of the results obtained for genetic diversity of Gli

93 alleles in wheats, were retrieved from papers published earlier (Supplementary material 2). In

94 the map (Figure 1), Northern Kazakhstan and two nearby regions in Russia with wheat Breeding

95 Research Organisations - Saratov (European part) and Omsk (Siberia) are indicated by ovals.

96 Briefly, Northern Kazakhstan is located at latitude $51^{\circ}-55^{\circ} \mathrm{N}$ and longitude $61^{\circ}-79^{\circ} \mathrm{E}$, with a

97 territory of about $565 \mathrm{~K} \mathrm{~km}^{2}$ comprised largely of steppe or low-hilled forest. The strong

98 continental climate is characterized by a cold and long winter with high winds, but a hot and

99 short summer season. Average winter/summer temperatures are about $-18^{\circ} \mathrm{C}$ and $20^{\circ} \mathrm{C}$ but

100 extreme levels of $-45^{\circ} \mathrm{C}$ and $41^{\circ} \mathrm{C}$, respectively can also be reached.

101

102 [Insert Figure 1 here]

103

104

Electrophoresis and identification of Gli alleles

105 Polyacrylamide gel electrophoresis was carried out following a method published earlier

106 (Metakovsky \& Novoselskaya 1991). Gliadins were extracted from individually milled seeds by

107 adding $150 \mu \mathrm{L}$ of $70 \%$ ethanol. Acrylamide polymerization was initiated by $50 \mu \mathrm{L}$ of $3 \% \mathrm{H}_{2} \mathrm{O}_{2}$

108 in $45 \mathrm{~mL}$ of gel solution. A vertical gel tank, model VE-20 (Helicon, Russia) was used and the

109 gels were $17.8 \times 17.5 \times 1(\mathrm{~mm})$ in size. Electrophoresis was conducted at optimal temperature

110 below $20^{\circ} \mathrm{C}$, at $520 \mathrm{~V}$ for $4 \mathrm{~h} .10 \%$ trichloroacetic acid supplied with $0.05 \%$ of Coomassie

111 Brilliant Blue R-250 in ethanol (Sigma-Aldrich, USA) was used for gel fixation and staining.

112 The identification of gliadin components was conducted using the Protein Catalogue

113 (Metakovsky, 1991). Genes that encoded gliadins were identified in accordance to the Gene

114 Catalogue developed by (McIntosh at al., 2008) for Gli-1 (-A1, -B1, and -D1) and for Gli-2 (-A2,

$115-B 2$, and $-D 2)$. Alleles of the Gli locus were designated as additional Latin letters and total GGFs

116 were used as recommended for wheat cv. Chinese Spring with the following in full GGF: Gli-

117 Ala, Gli-B1a, Gli-Dla, Gli-A2a, Gli-B2a, Gli-D2a; and abbreviated GGF: a, a, a, a, a, $\boldsymbol{a}$.

118

119 Computer and statistical analysis 
120 Intra-population diversity $\left(\mu \pm S_{\mu}\right)$ and frequency of rare alleles $\left(h \pm S_{h}\right)$ were calculated following

121 the method published by Zhivotovsky (Zhivotovsky, 1991), while genetic diversity $(H)$ was

122 calculated by the formula described by Nei, where $p_{i}$ is the frequency of alleles $(\mathrm{Nei}, 1973)$ :

123

$$
H=1-\sum p_{i}^{2}
$$

124 Phylogenetic tree construction and clustering analysis among the studied wheat genotypes was

125 carried out using the computer program software Statistica 6.0. (Statsoft, USA) following

126 instructions for Ward's method with Manhattan distances and applied for GGFs. The 'Data

127 Standardization' option was applied to transform the allele identifications in letters into numbers

128 suitable for the computer program software

129 (http://documentation.statsoft.com/STATISTICAHelp.aspx?path=Cluster/ClusterAnalysis/Exam

130 ples/Example1JoiningTreeClustering).

131

132 Results

\section{Gli allele diversity}

134 The alleles of loci Gli-1 and Gli-2 identified in the wheat germplasm collection (70 accessions)

135 and their GGFs are presented in Supplementary material 1. Most of the studied wheats were

136 monomorphic (76\%) while the remaining 24\% accessions were polymorphic. Grains of such

137 polymorphic wheats consisted of a mixture of genotypes, with variable alleles in one or more Gli

138 loci. For example, several biotypes of gliadins were present in polymorphic cv. Lutescence 65

139 with various spectra of gliadin components in three zones, $\alpha$-, $\beta$ - and $\gamma$, but identical in $\omega$ - zone

140 (Figure 2, lanes 1-3). Plants of cv. Byrlestik were monomorphic and represent the single type of

141 gliadin spectrum (Figure 2, lanes 5-7). In general, the inter-cultivar polymorphic alleles of Gli

142 encode the biosynthesis of gliadin components located in all four zones ( $\alpha$-, $\beta$-, $\gamma$ - and $\omega$ - zones)

143 of the gliadin spectrum on the polyacrylamide gel electrophoregram (Figure 2).

\section{5 [Insert Figure 2 here]}

147 At the Gli-1 locus, the highest frequencies were found in alleles Gli-Alf $(38.7 \%),-B 1 \boldsymbol{e}(62.1 \%)$, 148 and $-D 1 a(33.6 \%)$. In contrast, the level of highest frequency of alleles was smaller at the Gli-2 149 locus and comprising Gli-A2b (17.14\%), -B2t (12.9\%), and -D2q (23.6\%). Therefore, the GGF of 
150 the majority of wheats bred and cultivated in Northern Kazakhstan is: $\boldsymbol{f}, \boldsymbol{e}, \boldsymbol{a}, \boldsymbol{b}, \boldsymbol{t}, \boldsymbol{q}$, based on

151 highest frequencies of the alleles. In total, results of gliadin electrophoresis revealed six and eight

152 alleles in Gli-B1 and Gli-D1 loci, respectively, 14 alleles in each of three loci, Gli-A1, Gli-A2

153 and Gli-D2, and 17 alleles in Gli-B2 locus (Figure 3).

[Insert Figure 3 here]

156

Levels of genetic diversity $(H)$, intra-population diversity $(\mu)$ and frequencies of rare alleles $(h)$

in 70 wheat accessions from Northern Kazakhstan were calculated based on allele frequencies in

Gli loci from Supplementary material 1 and are presented in Table 1A. For comparison, four other studies of wheat from Northern Kazakhstan (Supplementary material 2) with partial overlap in the accessions studied were joined together with the current study, with the combined results for 139 wheat accessions in total from Northern Kazakhstan presented in Table 1B.

\section{[Insert Table 1 here]}

Most of the results presented in Table 1A and 1B are very similar, indicating for a representable subset of 70 wheat accessions for Northern Kazakhstan. For example, genetic diversity, $H$, was highest in loci Gli-B2 $(0.92 / 0.93)$ and Gli-A2 (0.89/0.90), while smallest $H=0.53 / 0.45$ were calculated for Gli-B1 in both parts of Table 1. The same trend has been found for intrapopulation diversity $\mu=15.13 / 17.37$ and $12.04 / 14.44$ for alleles of loci Gli-B2 and Gli-A2, respectively, with maximal number of the identified alleles (17 and 14 alleles, respectively). In contrast, the locus $G l i-B 1$ had the smallest value of $\mu=3.65 / 4.33$ with only six identified alleles as the smallest number in this study and with highest frequency of the Gli-Ble allele (Table 1,

\section{Figure 3).}

The structure of intra-population diversity can be characterised by the frequencies of rare alleles (h). A population can be estimated as 'balanced' if values of $h$ are less than 0.3 and as small as possible (Zhivotovsky, 1980). Therefore, the most balanced for intra-population diversity was

179 found for locus Gli-B2 $(h=0.11 / 0.13)$, while locus Gli-B1 had the highest value for $h(0.39 / 0.52)$ due to the highest frequency of a single allele, Gli-Ble. 
181

182 The highest frequencies of each gliadin allele in the combined group of 139 wheat accessions 183 were accounted as: Gli-Alf (39.3\%), -Ble (71.9\%), -Dla (41.0\%), -A2q (17.8\%), -B2t (13.5\%), 184 and $-D 2 \boldsymbol{q}(20.4 \%)$. The GGF in the analysis of 139 wheat accession was as follows: $\boldsymbol{f}, \boldsymbol{e}, \boldsymbol{a}, \boldsymbol{q}, \boldsymbol{t}$, $185 q$, and almost identical to those identified in the current study, with only a single difference for

186 Gli-A2-q or $-\boldsymbol{b}$. Therefore, the most typical GGF in wheat accessions from Northern Kazakhstan 187 can be identified as: $\boldsymbol{f}, \boldsymbol{e}, \boldsymbol{a}, \boldsymbol{q}+\boldsymbol{b}, \boldsymbol{t}, \boldsymbol{q}$.

188

Comparative phylogenetic analysis of the biodiversity of gliadin-coding loci in bread wheat 190 from Northern Kazakhstan and other origins

191 A gliadin dendrogram (Figure 4) was established based on a cluster analysis of our combined 192 current and previously published results of allele variation in the Gli loci and GGF, in wheat 193 originating from Northern Kazakhstan (Supplementary materials 1 and 2) and other publicly 194 available data for wheat from other countries (Table 2).

195

[Insert Figure 4 here]

197

198

[Insert Table 2 here]

199

200

Two major Clades (designated as A and B) were found in GGF, with strong separation of the 201 analysed accessions. Wheat genotypes from Australia, America and Western Europe form Clade A, while the more diverse Clade B includes accessions with Gli alleles mostly distributed in Eastern Europe and Asia, with the exception of the UK. As expected, all wheat cultivars from Northern Kazakhstan had GGF most closely related to Russian wheats, particularly those developed in the two big Breeding Research Institutes in Saratov and Omsk, in the European and Siberian part of Russia, respectively. These regions are very close to Northern Kazakhstan geographically (Figure 1), and also have a long history of exchange of wheat germplasms within 208 the former Soviet Union.

\section{Discussion}


211 The presented study is an important part of the breeding program for seed quality in wheat, to

212 illustrate breeder selections for wheat genotypes with various combinations of gliadin alleles.

213 The received results can be used as the basis of a breeding strategy for wheat genotype selection

214 with preferred GGF and favourable combinations of Gli alleles. In the current study, genetic

215 origin, gliadin characteristics and the value of breeding for alleles in each of gliadin-coding loci

216 in 70 wheat accessions will be discussed in separate sub-sections.

217

218 Locus Gli-A1

219 Fifteen Gli-Al alleles were identified in the current study in wheat cultivars from Northern

220 Kazakhstan, out of 29 alleles published in the recent Catalogue of gliadin-coding genes

221 (Metakovsky et al., 2018). The highest frequency (0.39) was found in genotypes with allele $\boldsymbol{f}$.

222 The wide-spread occurrence of the allele $\boldsymbol{f}$ in 27 wheat accessions from Northern Kazakhstan out

223 of the 70 studied seems to be related to introgression of the following high grain quality

224 cultivars: Cesium $111(f)$, Albidum $24(f)$ and Saratovskaya $29(j+f)$ in the early stages of the

225 wheat breeding process in Kazakhstan (Metakovsky et al., 2006).

226

227 The possible origin and spread of other Gli-Al alleles, $\boldsymbol{i}, \boldsymbol{o}$ and $\boldsymbol{b}$, is likely also related to wheat

228 cultivars from Russia. For example, a series of cultivars entitled Omskaya 20, 22 and 23,

229 originating from the forest-steppe zone of South-Western Siberia, with allele Gli-Alo, seems to

230 be used in the exchange breeding process (Metakovsky et al., 2006). This conclusion is similar to

231 those in our previous published results using a different set of wheat cultivars from Northern

232 Kazakhstan (Utebayev et al., 2016).

233

234 Locus Gli-B1

235 Very limited genetic diversity was found in the Gli-B1 locus, where the single allele $\boldsymbol{e}$ showed

236 the absolute highest frequency at $62 \%$ (Figure 3). It is important to note that this allele is quite

237 widely distributed, especially in southern regions of European Russia (Novoselskaya-Dragovich

238 et al., 2003) as well as in South-Eastern and South-Western Siberia, which are close and directly

239 neighbouring to Northern Kazakhstan, respectively (Nikolaev, Pukhal'sky \& Upelniek, 2009).

240 The occurrence and quite frequent distribution of the allele Gli-Ble may be directly related to the

241 actively-used popular Russian drought tolerant cultivars with elite grain quality from the Saratov 
242 region: Albidum $43(\boldsymbol{f}, \underline{\boldsymbol{e}}, \boldsymbol{a}, \boldsymbol{q}, \boldsymbol{o}, \boldsymbol{a})$, Lutescence $62(\boldsymbol{j}, \underline{\boldsymbol{e}} \boldsymbol{\boldsymbol { a }}, \boldsymbol{q}, \boldsymbol{o}, \boldsymbol{a})$, and Saratovskaya $29(\boldsymbol{j}+\boldsymbol{f}, \underline{\boldsymbol{e}}$, $243 \boldsymbol{a}, \boldsymbol{q}+\boldsymbol{s}, \boldsymbol{q}+\boldsymbol{s}, \boldsymbol{e})($ Metakovsky et al., 2006). However, these cultivars had some disadvantages,

244 particularly a sensitivity to a range of diseases (Morgounov, Rosseeva \& Koyshibayev, 2007). 245

246 The second allele, Gli-Blb, with three-fold less frequency (29\%) has a much wider distribution 247 among wheat cultivars from Scandinavian countries to Australia (Metakovsky et al., 2018) and 248 may therefore indicate the wide adaptability of genotypes with this allele. It is very likely that the $249 G l i-B 1 \boldsymbol{b}$ allele is originated from historic and classical winter wheat cultivars bred in the former 250 Soviet Union, Besostaya $1(\boldsymbol{b}, \underline{\boldsymbol{b}}, \boldsymbol{b}, \boldsymbol{b}, \boldsymbol{b}, \boldsymbol{b})$ and Mironovskaya $808(\boldsymbol{f}, \underline{\boldsymbol{b}}, \boldsymbol{g}, \boldsymbol{n}, \boldsymbol{m}, \boldsymbol{e})$ (Metakovsky 251 et al., 2006).

\section{Locus Gli-D1}

254 There were eight alleles identified in this locus in the studied wheat accessions, which is exactly 255 half of all that were published in the recent Catalogue of gliadin-coding loci (Metakovsky et al., 2018). Three alleles showed the highest range of frequencies: Gli-D1a $0.34 ;-\boldsymbol{b}, 0.31$; and $-\boldsymbol{f}$, 0.16 (Figure 3). However, the spectrum of genetic diversity in the present study slightly differed from our paper published earlier with another set of bread wheat accessions from Northern Kazakhstan, where only four Gli-Dl alleles were identified with the following frequencies: allele $\boldsymbol{a}, 44.2 \%$; and each of alleles $\boldsymbol{f}$ and $\boldsymbol{i}, 23.3 \%$, respectively (Utebayev et al., 2016).

Similar to those indicated for other alleles above, Russian wheat cultivars were widely used in the initial breeding programs in Northern Kazakhstan. Therefore, it is very likely that the most commonly distributed allele, $\boldsymbol{a}$, is originated from one or several cultivars, particularly Albidum

265

266

267

268 43, Lutescence 62, or Saratovskaya 29 (Chernakov \& Metakovsky 1994; Nikolaev, Pukhal'sky \& Upelniek, 2009). Additionally, this allele, Gli-Dla, had quite high frequencies among wheat cultivars in Southern Kazakhstan, with a very different environment, but the origin of the allele $\boldsymbol{a}$ from the former Soviet Union wheat germplasm genepool is not in doubt (Absattarova, 2002). This statement is in complete consensus with data for GGF in Kazakh wheats published in a recent review (Metakovsky et al., 2018). The comparison of world-wide distribution of Gli allele $\boldsymbol{a}$ among wheat genotypes bred and grown in Croatia, Finland and Spain (Sontag-Strohm ,1997; 
272 Metakovsky et al., 2018), indicated for a possible association between allele Gli-Dla with

273 adaptability of wheat plants to various environments.

274

275 It is important to note that two Gli-Dl alleles, $\boldsymbol{a}$ and $\boldsymbol{f}$, encode the synthesis of almost identical

276

277

278

279

280

281

282

283

284

285

286

287

288

289

290

291

292

293

294

295

296

297

298

299

300

301

302

spectra of gliadin components. The only additional gliadin component present with smaller size in the $\gamma$-zone of protein electrophoresis was recorded in wheat genotypes Gli-Dl with allele $\boldsymbol{a}$ but not with allele $\boldsymbol{f}$. Therefore, it is hypothesised that wheat genotypes Gli-Dla and $\boldsymbol{f}$ can have very similar gliadin gene nucleotide sequences (Chebotar et al. 2012).

The moderately distributed allele $\boldsymbol{b}$ is also very likely to have originated from foreign wheat accessions introgressed earlier in the Kazakh breeding program. However, it is interesting that the Gli-DIb allele originates from a very different genepool of winter wheat, rather than spring wheat. This statement is based on published data showing a quite high distribution of the allele $\boldsymbol{b}$ among winter wheat, but not in spring wheat, in the former Soviet Union (Kozub et al., 2009; Novoselskaya-Dragovich et al., 2015). Therefore, we can speculate that the possible introgression of the Gli-Dlb allele from winter wheat can indicate for the wide adaptability of wheat genotypes, regardless of their responses to cold and vernalisation.

\section{Locus Gli-A2}

The Gli-2 gene is much more diverse in wheat, where the smallest number of alleles were recorded in Gli-A2 and accounted for 14 (Figure 3) of the 39 registered in the recent Catalogue of Gli alleles (Metakovsky et al., 2018). The most commonly distributed alleles among the studied wheat cultivars from Northern Kazakhstan were: Gli-A2b (17.1\%), $\boldsymbol{f}(12.1 \%)$, and $-\boldsymbol{q}$ $(15.0 \%)$. The first allele $\boldsymbol{b}$ was very typical for wheat cultivars from very diverse geographical regions and had similarities to wheats from the UK, Eastern Europe and the Krasnodar region in the southern part of Russia (Metakovsky et al., 2018). Winter wheat germplasm accessions also had about $22 \%$ of the allele Gli-A2b (Novoselskaya-Dragovich et al., 2015), and this allele is particularly spread among wheat cultivars with high tolerance to cold temperatures (Markarova, 2015). This leads us to the conclusion that the Gli-A2b allele may be associated with genotypes with high adaptability to unfavourable conditions for plant growth. 
303 The allele Gli-A2f was present in wheat cultivars originating from the Saratov region, Russia

304 (Novoselskaya-Dragovich, Fisenko \& Puhalskii, 2013) and in some winter wheat cultivars

305 (Novoselskaya-Dragovich et al., 2015) but is known to show the highest frequencies in spring 306 wheat from Mexico and Portugal (Metakovsky et al., 2018).

308 The third allele, Gli-A2q, was very likely introgressed and spread widely in wheat cultivars in

309 Northern Kazakshtan from germplasm originating from the nearby Russian regions of Saratov

310 and Omsk (Novoselskaya-Dragovich, Fisenko \& Puhalskii, 2013). For example, cv. Lutescence

31162 was widely used for hybridisations in Kazakhstan with GGF (j, $\boldsymbol{e}, \boldsymbol{a}, \boldsymbol{q}, \boldsymbol{o}, \boldsymbol{a})$ from the Saratov

312 Breeding Institute, and it was consequently bred during individual selection of plants of the

313 original historical cv. Poltavka $(\boldsymbol{f}+\boldsymbol{j}, \boldsymbol{e}, \boldsymbol{a}, \boldsymbol{q}+\boldsymbol{k}, \boldsymbol{o}, \boldsymbol{a}+\boldsymbol{e})($ Rutz, 2005; Metakovsky et al., 2006). The

314 influence of the wheat genepool originating from the Saratov region on the wheat breeding

315 program in Northern Kazakhstan was described in the genetic polymorphism of Gli alleles in

316 papers published a relatively long time ago (Sozinov, Metakovsky \& Koval, 1986; Metakovsky et

317 al., 1988). However, among Kazakh wheat cultivars with elite quality of grain, only the allele

318 Gli-A2q had the highest frequency of distribution, indicating for a possible genetic association

319 with high grain quality (Dobrotvorskaya et al., 2009).

320

321

\section{Locus Gli-B2}

322 Seventeen out of 45 Gli alleles described in recent Catalogues (Metakovsky et al., 2018) were

323 identified and analysed in the current study. The highest frequency was found for the allele Gli-

$324 B 2 t, 12.8 \%$, followed by $10.7 \%$ for alleles $\boldsymbol{- b}$ and $-\boldsymbol{g}$, respectively. The origin of the first allele $\boldsymbol{t}$

325 remains unclear because it was registered as a minor Gli allele in some modern wheat cultivars

326 from the Omsk Breeding Station, Russia (Chernakov \& Metakovsky, 1994). We can propose that

327 the origin of the allele Gli-B2t is likely related to the old Russian cv. Cesium 111 used for

328 hybridisations with GGF $(\boldsymbol{f}, \boldsymbol{m}, \boldsymbol{i}, \boldsymbol{j}, \boldsymbol{t}, \boldsymbol{i})$ and published earlier (Metakovsky et al., 2006;

329 Morgounov, Rosseeva \& Koyshibayev, 2007).

330

331 The occurrence and distribution of allele Gli-B2b is definitely related to the use and introgression

332 of wheat accessions from Eastern Europe and Russia, where this allele was exclusively present

333 (Metakovsky et al., 2018). In contrast, the Gli allele $\boldsymbol{g}$ very likely originates from one of the wide 
334 geographically dispersed countries such as the Scandinavian group (Metakovsky et al., 2018), the

335 UK (Chernakov \& Metakovsky, 1994), France (Metakovsky \& Branlard, 1998), and China

336 (Novoselskaya-Dragovich et al., 2011).

337

\section{Locus Gli-D2}

339 The sixth and last gliadin-coding locus, Gli-D2, was present with 14 alleles. The three most

340 widely distributed alleles were $\boldsymbol{q}, \boldsymbol{b}$ and $\boldsymbol{a}$, with corresponding percentage of frequencies: $23.5 \%$,

$341 \quad 17.8 \%$ and $11.4 \%$, respectively. In the comparison with gliadin allele distributions, Gli-D2b was

342 originated from Russian wheat germplasm (Metakovsky et al., 2018). Both $\boldsymbol{q}$ and $\boldsymbol{a}$ alleles were

343 widely distributed in local wheats from Northern Kazakhstan, and regarding our previous study,

344 allele Gli-D2a was for the first time found in three Kazakh wheat cultivars, Milturum 45,

345 Tzelinogradka and Snegurka (Utebayev et al., 2016). These three cultivars were included in

346 wheat breeding in Northern Kazakhstan as genetic donors, and the first two of them (Milturum

34745 and Tzelinogradka) were bred from original, old and polymorphic cv. Cesium 111 with GGF

$348-\boldsymbol{f}, \boldsymbol{m}, \boldsymbol{i}, \boldsymbol{j}, \boldsymbol{t}, \underline{\boldsymbol{a}}+\boldsymbol{e}$ (Metakovsky et al., 2006). It is more likely that modern Kazakh wheat

349 genotypes with allele Gli-D2a had a pedigree progenitor from one of the biotypes of cv. Cesium

350 111. Less likely, but still possible, is that the origin of the $\boldsymbol{a}$ allele is from other countries where it

351 was found, such as Croatia, Germany, France, Holland, Italy, Scandinavian countries, Spain or

352 the UK (Metakovsky et al., 2018), indicating for a possible wide interest for wheat breeding

353 programs.

354

355 Comparison of genetic diversity between Gli-1 and Gli-2 alleles

356 In both our current and previous study (Utebayev et al., 2016), the three most popular and widely

357 distributed modern spring bread wheat cultivars from Northern Kazakhstan with elite grain

358 quality have the following GGF: Akmola $2(\boldsymbol{g}, \boldsymbol{e}, \boldsymbol{a}, \boldsymbol{i}, \boldsymbol{e}, \boldsymbol{s})$, Astana $(\boldsymbol{g}+\boldsymbol{j}, \boldsymbol{e}, \boldsymbol{f}+\boldsymbol{i}, \boldsymbol{p}, \boldsymbol{h}, \boldsymbol{b})$, and

359 Karabalykskaya $90(\boldsymbol{i}+\boldsymbol{m}+\boldsymbol{f}, \boldsymbol{e}, \boldsymbol{a}+\boldsymbol{g}, \boldsymbol{q}+\boldsymbol{l}, \boldsymbol{v}, \boldsymbol{a})$ (Supplementary material 2). These cultivars have

360 a similar composition of alleles in the gene Gli-1, with three homeologous loci $(-A 1,-B 1$ and -

$361 \mathrm{D} 1)$ to wheat cultivars with very high grain quality from the Russian Breeding Institutes, Saratov

362 and Omsk. Therefore, it was hypothesised that allele compositions in each of three loci of Gli-1

363 were directly related to grain and baked bread quality and its improvement (Li et al. 2009;

364 Novoselskaya-Dragovich, Fisenko \& Puhalskii, 2013). In contrast, allele compositions in the 
365 second gene Gli-2 with three homeologous loci (-A2, $-B 2$ and $-D 2)$ located in chromosome group

366 6, were genetically associated with possible adaptation of plants to a dry environment

367 (Novoselskaya-Dragovich, Fisenko \& Puhalskii, 2013).

368

369

Such a conclusion, made from the comparison between Gli-1 and Gli-2 genes, may explain how

370 non-pedigree related wheat cultivars from various geographic regions with a different climate have very similar or identical compositions of Gli-1 alleles. This is because one of the main targets of wheat breeding is the production of wheat with elite quality of grain and baked bread, where genetic diversity for allele composition in Gli-1 is much smaller than in Gli-2: 14, 6 and 8 alleles for $G l i-A 1,-B 1$ and $-D 1$; and 14,17 and 14 alleles for Gli-A2, $-B 2$ and $-D 2$, respectively (Figure 3). It is possible that a single perfect pedigree genotype with excellent grain quality was used as a progenitor in many modern wheat cultivars, providing limited genetic variability in allele composition of Gli-1. In contrast, the Gli-2 gene, with much wider variability in allele compositions, was more likely involved in plant adaptation to a dry environment. Because such environments are quite variable in different countries and geographic regions, it may be reflected in and explain the higher variability in allele diversity in Gli-2. The presented results reflect the efforts of wheat breeders over many years of artificial selection based on phenotyping variability in grain quality and tolerance to dry environments, as apparent in the results of genetic diversity in both gliadin-coding genes based on gliadin analyses.

\section{Conclusions}

386

387

388
Genetic diversity in the alleles of gliadin-coding genes Gli-1 and Gli-2 was studied, and gliadin genetic formulas were established following the results of gliadin electrophoresis in a set of 70 spring bread wheat cultivars from Northern Kazakhstan. The Gli alleles with highest frequencies in the studied wheat material were identified as follows: Gli-Alf $(39.3 \%),-B 1 \boldsymbol{e}(71.9 \%),-D 1 \boldsymbol{a}$ $(41.0 \%),-A 2 \boldsymbol{q}(17.8 \%),-B 2 \boldsymbol{t}(13.5 \%)$, and $-D 2 \boldsymbol{q}(20.4 \%)$. This allele combination of both Gli genes was the most widely distributed in Northern Kazakhstan, and genotypes with such gliadin formula can be used as prospective breeding material for elite grain quality, better adaptability to the dry environment of the Northern Kazakhstan region and for wheat breeding under similar conditions. 


\section{Acknowledgments}

397 We thank Carly Schramm for critical comments and English editing.

398

399

400

401

402

403

404

405

406

407

408

409

410

411

412

413

414

415

416

417

418

419

420

421

\section{References}

Absattarova AS. 2002. Identification of Kazakhstan agroecotypes winter common wheat cultivars using of gliadin components blocks. Dissertation of the Candidate of Biological Sciences. Kazakh Research Institute of Agriculture and Plant Growing. Almalybak (in Russ.).

Aguiriano E, Ruiz M, Fité R, Carrillo JM. 2008. Genetic variation for glutenin and gliadins associated with quality in durum wheat (Triticum turgidum L. ssp. turgidum) landraces from Spain. Spanish Journal of Agricultural Research 6(4):599-609 DOI 10.5424/sjar/2008064-353

Al-Doss AA, Al-Hazmi AS, Dawabah AAM, Abdel-Mawgood AA, Al-Rehiayani SM, Solaiman A, Moustafa K, Motawei M. 2010. Impact of Cre and peroxidase genes of selected new wheat lines on cereal cyst nematode (Heterodera avenae Woll) resistance. Australian Journal of Crop Science 4(9):737-743.

Borisjuk N, Kishchenko O, Eliby S, Schramm C, Anderson P, Jatayev S, Kurishbayev A, Shavrukov Y. 2019. Genetic modification for wheat improvement: from transgenesis to genome editing. BioMed Research International 2019: 6216304.

Burridge AJ, Wilkinson PA, Winfield MO, Barker GL, Allen AM, Coghill JA, Waterfall C, Edwards KJ. 2018. Conversion of array-based single nucleotide polymorphic markers for use in targeted genotyping by sequencing in hexaploid wheat (Triticum aestivum). Plant Biotechnology Journal 16(4):867-876 DOI 10.1111/pbi.12834

Bushuk W, Zillman RR. 1978. Wheat cultivar identification by gliadin electrophoregrams. I. Apparatus, method and nomenclature. Canadian Journal of Plant Science 58:505-515 DOI 10.4141/cjps78-076

Chebotar SV, Blagodarova EM, Kurakina EA, Semenyuk IV, Polishchuk AM, Kozub NA, Sozinov IA, Khokhlov AN, Ribalka AI, Sivolap YuM. 2012. Genetic polymorphism of loci determining 
422

423

424

425

426

427

428

429

430

431

432

433

434

435

436

437

438

439

440

441

442

443

444

445

446

bread making quality in Ukrainian wheat varieties. Vavilov Journal of Genetics and Breeding 16(1):87-98 (In Russ).

Chernakov VM, Metakovsky EV. 1994. Diversity of gliadin-coding locus allelic variants and evaluation of genetic similarity of common wheat varieties from different breeding counters. Genetika 30(4):509-517 (in Russ).

Dobrotvorskaya TV, Dragovich AY, Martynov SP, Pukhal'skii VA. 2009. Genealogical and statistical analyses of the inheritance of gliadin-coding alleles in a model set of common wheat Triticum aestivum L. cultivars. Russian Journal of Genetics 45(6):685-695 DOI 10.1134/S1022795409060088

Ghanti SK, Sujata KG, Rao S, Udayakumar M, Kishor PBK. 2009. Role of enzymes and identification of stage-specific proteins in developing somatic embryos of chickpea (Cicer arietinum L.). In Vitro Cellular and Developmental Biology - Plant 45:667-672 DOI 10.1007/s11627-0099197-7

Hailegiorgis D, Lee CA, Yun SJ. 2017. Allelic variation at the gliadin coding loci of improved Ethiopian durum wheat varieties. Journal of Crop Science and Biotechnology 20(4):287-293 DOI 10.1007/s12892-017-0106-0

Henry RJ, Furtado A, Rangan P. 2018. Wheat seed transcriptome reveals genes controlling key traits for human preference and crop adaptation. Current Opinion in Plant Biology 45:231-236 DOI 10.1016/j.pbi.2018.05.002

ISO 898:1993, Wheat - Identification of varieties by electrophoresis.

Jatayev S, Kurishbaev A, Zotova L, Khasanova G, Serikbay D, Zhubatkanov A, Botayeva M, Zhumalin A, Turbekova A, Soole K, Langridge P, Shavrukov Y. 2017. Advantages of Amplifluor-like SNP markers over KASP in plant genotyping. BMC Plant Biology 17:254 DOI 10.1186/s12870-017-1197-X

Khan K, Hamada AS, Patek J. 1985. Polyacrylamide gel electrophoresis for wheat variety identification: effect of variables on gel properties. Cereal Chemistry 62(5):310-313. 
447

448

449

450

451

452

453

454

455

456

457

458

459

460

461

462

463

464

465

466

467

468

469

470

471

Khlestkina EK, Shumny VK. 2016. Prospects for application of breakthrough technologies in breeding: The CRISPR/Cas9 system for plant genome editing. Russian Journal of Genetics 52(7):676-687 DOI $10.1134 / \mathrm{S} 102279541607005 \mathrm{X}$

Kozub NA, Sozinov IA, Sobko TA, Kolyuchii VT, Kuptsov SV, Sozinov AA. 2009. Variation at storage protein loci in winter common wheat cultivars of the central forest-steppe of Ukraine. Cytology and Genetics 43(1):55-62 DOI 10.3103/S0095452709010101

Li Y, Song Y, Zhou R, Branlard G, Jia J. 2009. Detection of QTLs for bread-making quality in wheat using a recombinant inbred line population. Plant Breeding 128:235-243 DOI 10.1111/j.14390523.2008.01578.x

Liang Z, Chen K, Zhang Y, Liu J, Yin K, Qiu JL, Gao C. 2018. Genome editing of bread wheat using biolistic delivery of CRISPR/Cas9 in vitro transcripts or ribonucleoproteins. Nature Protocols 13(3):413-430 DOI 10.1038/nprot.2017.145

Markarova ZhR. 2015. Frost hardiness and yield of soft winter wheat cultivars and accessions in the Rostov region. Nauchny Zhurnal Rossiiskogo NII Problem Melioratsii 2(18):137-145 (in Russ).

McIntosh RA, Yamazaki Y, Devos KM, Dubkovsky J, Rogers J, Appels R. 2008. MacGene 2003. Catalogue of Gene Symbols for Wheat. In Proc. 10th Int. Wheat Genet. Symp. Paestum, Italy. Available at http://wheat.pw.usda.gov/ggpages/wgc/2003. (Accessed: 07. 03. 2019).

Melnikova NV, Ganeva GD, Popova ZG, Landjeva SP, Kudryavtsev AM. 2010. Gliadins of Bulgarian durum wheat (Triticum durum Desf.) landraces: genetic diversity and geographical distribution. Genetic Resources and Crop Evolution 57(4):587-595 DOI 10.1007/s10722-009-9497-0

Melnikova NV, Kudryavtseva AV, Kudryavtsev AM. 2012. Catalogue of alleles of gliadin-coding loci in durum wheat (Triticum durum Desf.). Biochimie 94(2):551-557 DOI 10.1016/j.biochi.2011.09.004

Metakovsky E, Melnik V, Quijano MR, Upelniek V, Carrillo JM. 2018. A catalog of gliadin alleles: Polymorphism of 20th-century common wheat germplasms. The Crop Journal 6(6):628-641 DOI $10.1016 /$ j.cj.2018.02.003 
472

473

474

475

476

477

478

479

480

481

482

483

484

485

486

487

488

489

490

491

492

493

494

495

Metakovsky EV, Branlard G, Graybosch RA, Bekes F, Cavanagh CR, Wrigley CW, Bushuk W. 2006. The gluten composition of wheat varieties and genotypes. Part I. Gliadin Composition Table. Available at https://www.aaccnet.org/initiatives/definitions/Documents/GlutenFree/I_Gliadin.pdf. (Accessed: 07. 03. 2019).

Metakovsky EV, Branlard G. 1998. Genetic diversity of French common wheat germplasm based on gliadin alleles. Theoretical and Applied Genetics 96:209-218 DOI 10.1007/s001220050729

Metakovsky EV, Branlard GP, Graybosch RA. 2006. Gliadins of common wheat: Polymorphism and genetics. In: Wrigley C, Bekes F, Bushuk W, ed. Gliadin and Glutenin: the Unique Balance of Wheat Quality. St. Paul American Association of Cereal Chemistry, 36.

Metakovsky EV, Koval SF, Movchan VK, Sozinov AA. 1988. Genetic formulas of gliadin in cultivars of common wheat of Northern Kazakhstan. Selekciya i Semenovodstvo 1:11-13 (in Russ).

Metakovsky EV, Novoselskaya AY. 1991. Gliadin allele identification in common wheat. 1. Methodological aspects of the analysis of gliadin pattern by one-dimensional polyacrylamide - gel electrophoresis. Journal of Genetics and Breeding 45:317-324.

Metakovsky EV. 1991. Gliadin allele identification in common wheat. 2 Catalogue of gliadin alleles in common wheat. Journal of Genetics and Breeding 45:325-344.

Morgounov A, Rosseeva L, Koyshibayev M. 2007. Leaf rust of spring wheat in Northern Kazakhstan and Siberia: incidence, virulence, and breeding for resistance. Australian Journal of Agricultural Research 58(9):847-853 DOI 10.1071/AR07086

Nei M. 1973. Analysis of gene diversity in subdivided populations. Proceedings of the National Academy of Sciences USA 70(12):3321-3323 DOI 10.1073/pnas.70.12.3321

Netsvetaev VP, Akinshina OV, Bondarenko LS. 2010. Genetic control of several $\alpha$-amylase isozymes in winter hexaploid wheat. Russian Journal of Genetics 48(3):347-349 DOI $10.1134 / \mathrm{S} 1022795412030106$ 
496 Nikolaev AA, Pukhal'sky VA, Upelniek VP. 2009. Genetic diversity of local spring bread wheats 497 (Triticum aestivum L.) of West and East Siberia in gliadin genes. Russian Journal of Genetics 45(2):189-197 DOI 10.1134/S1022795409020094

499

500

501

502

503

504

505

506

507

508

509

510

511

512

513

514

515

516

517

518

519

520

Nirmal RC, Furtado A, Rangan P, Henry RJ. 2017. Fasciclin-like arabinogalactan protein gene expression is associated with yield of flour in the milling of wheat. Scientific Reports 7:12539. DOI $10.1038 / \mathrm{s} 41598-017-12845-\mathrm{y}$

Nirmal RC, Furtado A, Wrigley C, Henry RJ. 2016. Influence of gene expression on hardness in wheat. PLoS One 11(10):e0164746 DOI 10.1371/journal.pone.0164746

Novoselskaya-Dragovich AY, Bespalova LA, Shishkina AA, Melnik VA, Upelniek VP, Fisenko AV, Dedova LV, Kudryavtsev AM. 2015. Genetic diversity of common wheat varieties at the gliadincoding loci. Russian Journal of Genetics 51(3):262-271 DOI 10.1134/S1022795415030102

Novoselskaya-Dragovich AY, Fisenko AV, Puhalskii VA. 2013. Genetic differentiation of common wheat cultivars using multiple alleles of gliadin coding loci. Russian Journal of Genetics 49(5):487496 DOI 10.1134/S1022795413020087

Novoselskaya-Dragovich AY, Fisenko AV, Yankovsky NK, Kudryavtsev AM, Yang Q, Lu Z, Wang D. 2011. Genetic diversity of storage protein genes in common wheat (Triticum aestivum L.) cultivars from China and its comparison with genetic diversity of cultivars from other countries. Genetic Resources and Crop Evolution 58(4):533-543 DOI 10.1007/s10722-010-9596-y

Novoselskaya-Dragovich AY, Krupnov VA, Saifulin RA, Pukhalskiy VA. 2003. Dynamics of genetic variation at gliadin-coding loci in Saratov cultivars of common wheat Triticum aestivum L. over eight decades of scientific breeding. Russian Journal of Genetics 39(10):1130-1137 DOI 10.1023/A:1026170709964

Obukhova LV, Shumny VK. 2016. The inheritance of endosperm storage proteins by the line of the Saratovskaya 29 cultivar of common wheat from its parental forms. Russian Journal of Genetics 52(1):49-55 DOI 10.1134/S1022795416010117 
521 Palosuo K, Varjonen E, Kekki OM, Klemola T, Kalkkinen N, Alenius H, Reunala T. 2001. Wheat $\omega-$

5225 gliadin is a major allergen in children with immediate allergy to ingested wheat. The Journal of Allergy and Clinical Immunology 108(4):634-638 DOI 10.1067/mai.2001.118602

Pastorello EA, Farioli L, Conti A, Pravettoni V, Bonomi S, Iametti S, Fortunato D, Scibilia J, Bindslev-Jensen C, Ballmer-Weber B, Robino AM, Ortolani C. 2007. Wheat IgE-mediated food allergy in European patients: $\alpha$-amylase inhibitors, lipid transfer proteins and low-molecular-weight glutenins. International Archives of Allergy and Immunology 144(1):10-22. DOI 10.1159/000102609

Qi PF, Wei YM, Yue YW, Yan ZH, Zheng YL. 2006. Biochemical and molecular characterization of gliadins. Molecular Biology 40(5):713-723 DOI 10.1134/S0026893306050050

Rutz RI. 2005. Breeding Center of Siberian Research Institute of Agriculture is a leader of Siberian breeding. Vestnik VOGiS 9(3):357-368 (in Russ.).

Salavati A, Sameri H, Boushehri AAS, Yazdi-Samadi B. 2008. Evaluation of genetic diversity in Iranian landrace wheat Triticum aestivum L. by using gliadin alleles. Asian Journal Plant Science 7(5):440-446 DOI 10.3923/ajps.2008.440.446

Sánchez-León S, Gil-Humanes J, Ozuna CV, Giménez MJ, Sousa C, Voytas DF, Barro F. 2018. Low-gluten, non-transgenic wheat engineered with CRISPR/Cas9. Plant Biotechnology Journal 16(4):902-910 DOI 10.1111/pbi.12837

Scheben A, Batley J, Edwards D. 2017. Genotyping-by-sequencing approaches to characterize crop genomes: choosing the right tool for the right application. Plant Biotechnology Journal 15(2):149161 DOI 10.1111/pbi.12645

Shavrukov Y. 2016. Comparison of SNP and CAPS markers application in genetic research in wheat and barley. BMC Plant Biology 16:11 DOI 10.1186/s12870-015-0689-9

Shewry PR, Halford NG. 2001. Cereal seed storage proteins: structures, properties and role in grain utilization. Journal of Experimental Botany 53(370):947-958 DOI 10.1093/jexbot/53.370.947 
545 Sontag-Strohm T. 1997. Gliadin and glutenin subunit alleles on group 1 chromosomes in Finnish spring wheats. Acta Agriculturae Scandinavica, Section B - Soil and Plant Science 47:98-105 DOI $10.1080 / 09064719709362446$

Sozinov AA, Metakovsky EV, Koval SF. 1986. Patterns of genotype formation in the breeding of the wheat. Vestnik Selskohozyaistvennoi Nauki 3:60-70 (in Russ.).

550

551

552

553

554

555

556

557

558

559

560

561

562

563

564

565

566

Sozinov AA, Poperelya FA. 1980. Genetic classification of prolamins and its use for plant breeding. Annales de Technologie Agricole 29:229-245.

Tkachuk R, Metlish VJ. 1980. Wheat cultivar identification by high voltage gel electrophoresis. Annales de Technologie Agricole 29:207-212.

\section{Utebayev M, Dashkevich S, Babkenov A, Shtefan G, Fahrudenova I, Bayahmetova S, Sharipova B,} Kaskarbayev Zh, Shavrukov Y. 2016. Application of gliadin polymorphism for pedigree analysis in common wheat (Triticum aestivum L.) from Northern Kazakhstan. Acta Physiologiae Plantarum 38(8):204 DOI 10.1007/s11738-016-2209-4

Xynias IN, Kozub NO, Sozinov IA. 2006. Seed storage protein composition of Hellenic bread wheat cultivars. Plant Breeding 125(4):408-410 DOI 10.1111/j.1439-0523.2006.01242.x

Zhang Y, Li D, Zhang D, Zhao X, Cao X, Dong L, Liu J, Chen K, Zhang H, Gao C, Wang D. 2018. Analysis of the functions of $T a G W 2$ homoeologs in wheat grain weight and protein content traits. The Plant Journal 94(5):857-866 DOI 10.1111/tpj.13903

Zhivotovsky LA. 1980. An index intrapopulation diversity. Zhurnal Obshchei Biologii 41(6):828-836 (in Russ).

Zhivotovsky LA. 1991. Population Biometrics. Moscow. Nauka RAN (in Russ). 


\section{Tables}

568 Table 1. Genetic diversity $(\mathrm{H})$, intra-population diversity $(\mu)$ and frequencies of rare alleles $(\mathrm{h})$

569 in 70 (A) and 139 combined (B) wheat accessions from Northern Kazakhstan

570

571 Table 2. GGF of wheat cultivars from various countries compared to the GGF of Northern

572 Kazakhstan wheats

573

574 


\section{Figure Legends}

576

577 Figure 1. A map of Kazakhstan and nearby regions of Russia. The red oval shows Northern

578 Kazakhstan, while the Russian regions, Saratov (European part) and Omsk (Siberia), are shown

579 in blue and black, respectively. The map was taken from the web-site:

580 http://theconversation.com/russias-borders-moscows-long-alliance-with-kazakhstan-is-strong-

581 but-not-unbreakable-36457.

582

583 Figure 2. Electrophoregram of the gliadin spectrum of polymorphic cv. Lutescence 65 (Lanes 1-

584 3) in comparison to cv. Besostaya 1 (Lane 4, used as a Standard) and monomorphic cv. Byrlestik

585 (Lanes 5-7). Sub-fractions $\alpha, \beta$, and $\gamma$ with polymorphic bands in Lanes 1-3 are indicated by 586 arrows.

587

588 Figure 3. Allele frequencies in Gli loci identified in the studied collection of 70 accessions of 589 spring bread wheat from Northern Kazakhstan.

590

591 Figure 4. Gliadin dendrogram showing the allele diversity in Gli loci of bread wheat from

592 Northern Kazakhstan and other countries. 


\section{Figure 1}

\section{A map of Kazakhstan}

Figure 1. A map of Kazakhstan and nearby regions of Russia. The red oval shows Northern Kazakhstan, while the Russian regions, Saratov (European part) and Omsk (Siberia), are shown in blue and black, respectively. The map was taken from the web-site:

http://theconversation.com/russias-borders-moscows-long-alliance-with-kazakhstan-is-strong-but-not-unbrea kable-36457

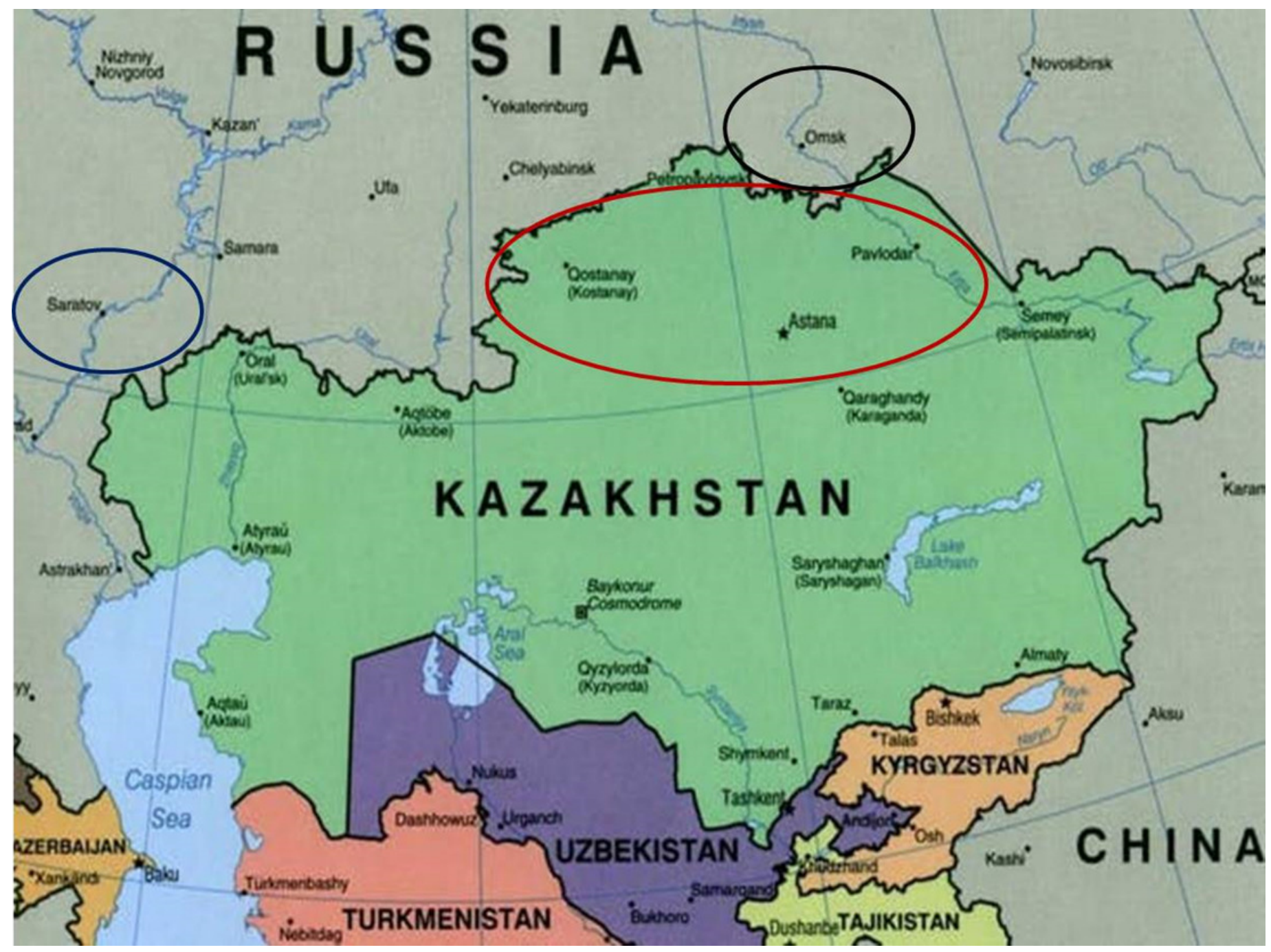




\section{Figure 2}

\section{Electrophoregram of the gliadin spectrum}

Figure 2. Electrophoregram of the gliadin spectrum of polymorphic cv. Lutescence 65 (Lanes 1-3) in comparison to cv. Bezostaya 1 (Lane 4, used as a Standard) and monomorphic cv. Byrlestik (Lanes 5-7). Subfractions $\alpha, \beta, \gamma$ and $\omega$ with polymorphic bands are indicated. 


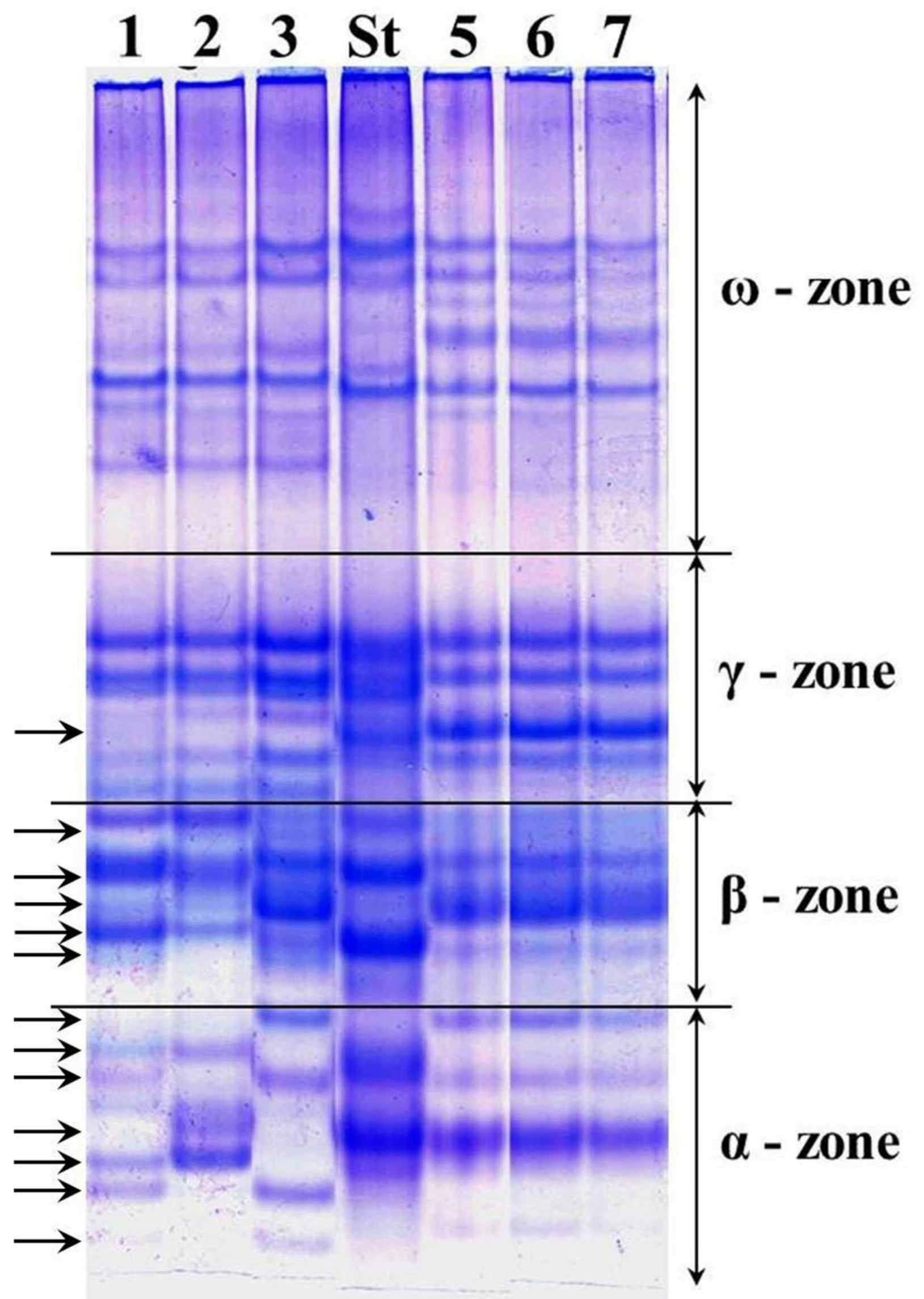




\section{Table $\mathbf{1}$ (on next page)}

Geneticdiversity $(H)$, intra-population diversity $(\mu)$ and frequencies of rare alleles $(h)$ in 70 (A) and 139 combined (B) wheat accessions from NorthernKazakhstan 
1 Table 1. Genetic diversity $(H)$, intra-population diversity $(\mu)$ and frequencies of rare alleles $(h)$

2 in 70 (A) and 139 combined (B) wheat accessions from Northern Kazakhstan

3

\begin{tabular}{|c|c|c|c|c|c|c|}
\hline \multirow{2}{*}{$\begin{array}{l}\text { Diversity } \\
\text { estimates }\end{array}$} & \multicolumn{6}{|c|}{ Gliadin-coding Gli loci } \\
\hline & $A 1$ & $B 1$ & D1 & $A 2$ & $B 2$ & $D 2$ \\
\hline \multicolumn{7}{|c|}{ A. 70 wheat accessions from Northern Kazakhstan (Supplementary material 1) } \\
\hline$H$ & 0.81 & 0.53 & 0.76 & 0.89 & 0.92 & \\
\hline$\mu \pm S$ & $3 \pm 0.73$ & $3.65 \pm 0.35$ & $6.00 \pm($ & $12.04 \pm 0.58$ & $15.13 \pm 0.64$ & \pm 0.63 \\
\hline$h \pm S_{h}$ & $0.25 \pm 0.05$ & $0.39 \pm 0.06$ & $0.25 \pm 0.05$ & $0.14 \pm 0.04$ & $0.11 \pm 0.04$ & $0.17 \pm 0.05$ \\
\hline \multicolumn{7}{|c|}{ B. 139 wheat accessions from Northern Kazakhstan (Supplementary materials 1 and 2) } \\
\hline$H$ & 0.80 & 0.45 & 0.75 & 0.90 & 0.93 & 0.89 \\
\hline$\mu \pm S_{\mu}$ & $12.32 \pm 0.71$ & $4.33 \pm 0.18$ & $6.78 \pm 0.40$ & $14.44 \pm 0.61$ & $17.37 \pm 0.57$ & $13.88 \pm 0.56$ \\
\hline$h \pm S_{h}$ & $0.32 \pm 0.04$ & $0.52 \pm 0.04$ & $0.32 \pm 0.04$ & $0.20 \pm 0.03$ & $0.13 \pm 0.03$ & $0.18 \pm 0.03$ \\
\hline
\end{tabular}

4 
Table 2 (on next page)

GGF of wheat cultivars fromvarious countries compared to the GGF of Northern Kazakhstan wheats 
1 Table 2. GGF of wheat cultivars from various countries compared to the GGF of Northern

2 Kazakhstan wheats

3

\begin{tabular}{|c|c|c|c|c|c|c|c|}
\hline \multirow{2}{*}{$\begin{array}{l}\text { Countries/r } \\
\text { egions }\end{array}$} & \multicolumn{6}{|c|}{ Gliadin coding loci Gli } & \multirow{2}{*}{ References } \\
\hline & $A 1$ & $B 1$ & $D 1$ & $A 2$ & $B 2$ & D2 & \\
\hline Australia & $g$ & $\bar{b}$ & $f$ & $c$ & $c$ & $w$ & Metakovsky et al., \\
\hline Canada & $m$ & $d$ & $j+a$ & $m$ & $c$ & $\boldsymbol{h}+\boldsymbol{m}$ & 2018 \\
\hline France & $a f+c$ & $b+f$ & $\boldsymbol{b}$ & $m$ & $o+c$ & $\boldsymbol{h}$ & \\
\hline Italy & $a$ & $g$ & $\boldsymbol{k}$ & $g+o$ & $\boldsymbol{o}$ & $a$ & \\
\hline Mexico & $o+a$ & $d+b$ & $b+a$ & $f$ & $c$ & $m+j$ & \\
\hline Portugal & $a$ & $c+l$ & $\boldsymbol{b}$ & $f$ & $c$ & $c+\dot{j}$ & \\
\hline Russia & & & & & & & \\
\hline (Saratov) & $f$ & $e$ & $a$ & $q$ & $s$ & $\boldsymbol{e}$ & \\
\hline Bulgaria & $b+a$ & $\boldsymbol{b}$ & $\boldsymbol{b}$ & $b+g$ & $\boldsymbol{b}$ & $\boldsymbol{b}$ & \\
\hline Croatia & $a+b$ & $e$ & $a$ & $e$ & $e$ & $m+a$ & \\
\hline Serbia & $a+b$ & $b+l$ & $\boldsymbol{b}$ & $b+g$ & $b$ & $b+a$ & \\
\hline Ukraine & $\boldsymbol{b}$ & $\boldsymbol{b}$ & $g$ & $f+b$ & $\boldsymbol{b}$ & $e$ & \\
\hline $\begin{array}{l}\text { Russia } \\
\text { (Omsk) }\end{array}$ & $f$ & $\boldsymbol{e}$ & $a$ & $q$ & $b$ & $a$ & $\begin{array}{l}\text { Novoselskaya- } \\
\text { Dragovich, Fisenko } \\
\& \text { Puhalskii, } 2013\end{array}$ \\
\hline Iran & $f$ & $f$ & $\boldsymbol{b}$ & $g+l$ & $\boldsymbol{o}$ & $a+n+h$ & $\begin{array}{l}\text { Salavati et al., } \\
2008\end{array}$ \\
\hline China & $o+a$ & $l+e$ & $a+f$ & $g+f$ & $I+\boldsymbol{h}$ & $b+a$ & $\begin{array}{l}\text { Novoselskaya- } \\
\text { Dragovich et al., } \\
2011\end{array}$ \\
\hline UK & $f$ & $f$ & $\boldsymbol{b}$ & $l$ & $g$ & $a$ & $\begin{array}{l}\text { Chernakov \& } \\
\text { Metakovsky, } 1994\end{array}$ \\
\hline $\begin{array}{l}\text { Northern } \\
\text { Kazakhstan }\end{array}$ & $f$ & $\boldsymbol{e}$ & $a$ & $q$ & $t$ & $q$ & Current study \\
\hline
\end{tabular}


Figure 3

\section{Allele frequencies}

Figure 3. Allele frequencies in Gli loci identified in the studied collection of 70 accessions of spring bread wheat from Northern Kazakhstan.

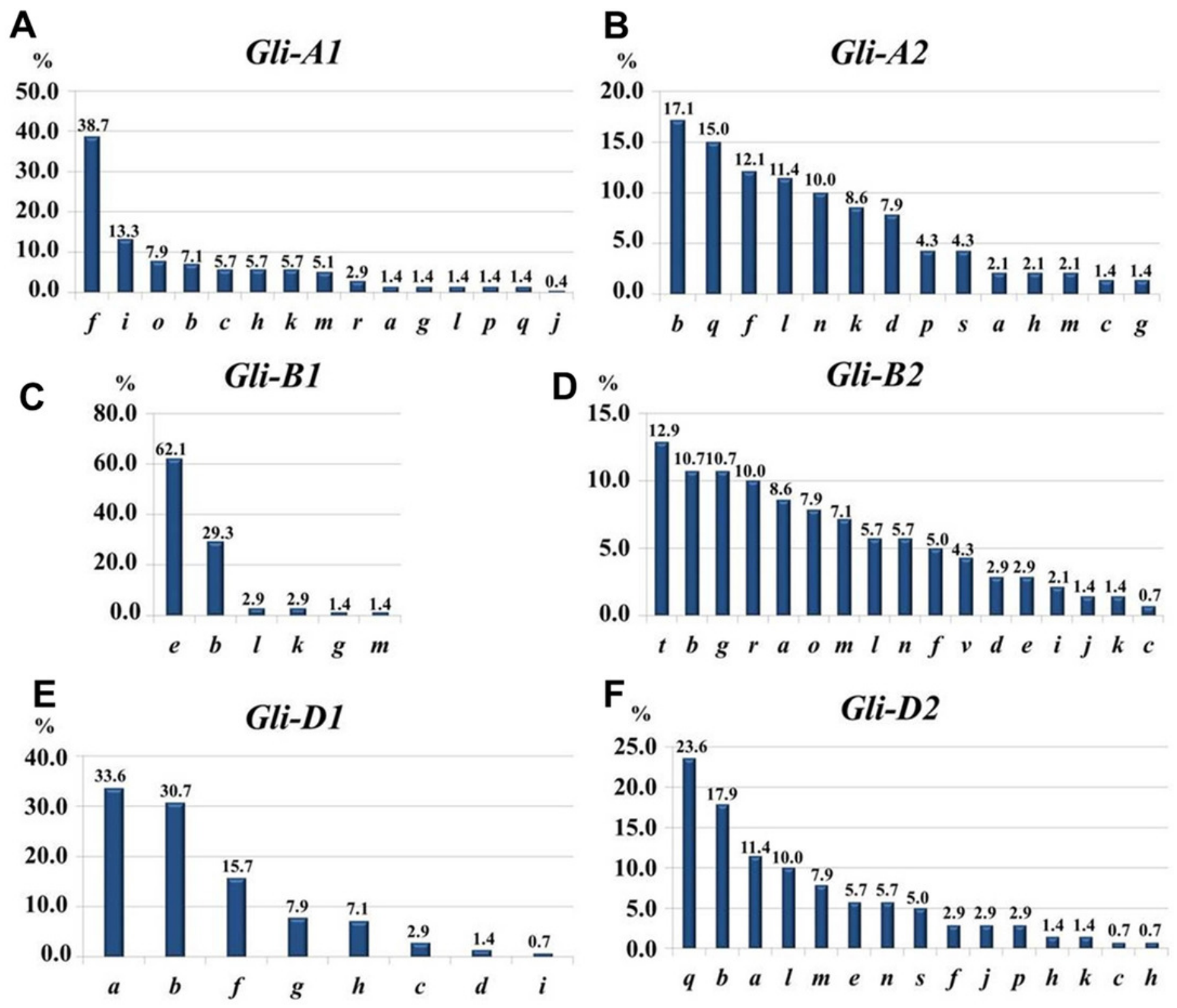


Figure 4

Gliadin dendrogram

Figure 4. Gliadin dendrogram showing the allele diversity in Gli loci of bread wheat from Northern Kazakhstan and other countries.

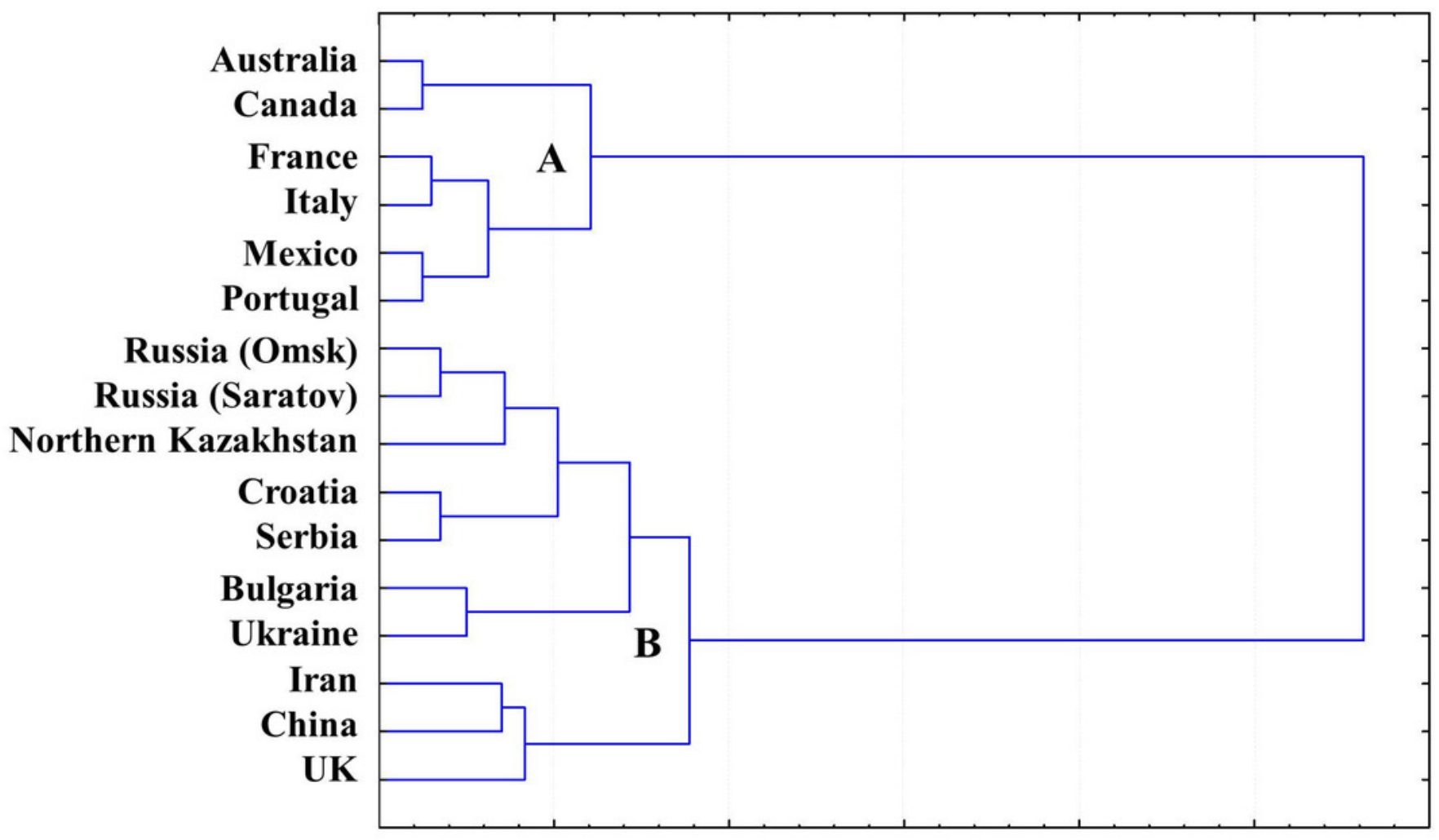

